\title{
Job autonomy, unscripted agility and ambidextrous innovation: analysis of Brazilian startups in times of the Covid-19 pandemic
}

\author{
Anderson Betti Frare \\ Graduate Program in Accounting, Federal University of Santa Catarina, \\ Florianopolis, Brazil, and \\ Ilse Maria Beuren \\ Accounting Department, Federal University of Santa Catarina, Florianopolis, Brazil
}

Brazilian startups in Covid-19 crisis

Received 6 January 2021 Revised 28 February 2021 3 April 2021

Accepted 19 April 2021

\begin{abstract}
Purpose - This study aims to analyze the influence of job autonomy and unscripted agility on ambidextrous innovation in startups in times of the Covid-19 pandemic.

Design/methodology/approach - A survey was conducted with founders and managers of Brazilian startups in the e-commerce segment, resulting in a sample of 84 startups. Symmetric (structural equation modeling) and asymmetric (fuzzy-set qualitative comparative analysis) analyses were performed. The variables' external financing and institutional ties were controlled.

Findings - The symmetric findings indicate that unscripted agility is a full mediator between job autonomy and ambidextrous innovation. The asymmetric findings offer two solutions for startups to achieve high ambidextrous innovation.

Research limitations/implications - The implications of the research for the literature are discussing elements associated with ambidextrous innovation, exploring the context of innovation in startups in times of crisis, specifically in the Covid-19 pandemic, and considering the role of resilience in startups.

Practical implications - The study provides informational inputs to founders and managers of startups on how job autonomy and unscripted agility can propel incremental and radical innovations.

Originality/value - This study provides new insights and success factors into startups, based on the discussion of entrepreneurship in times of crisis, as in the case of the Covid-19 pandemic.
\end{abstract}

Keywords Ambidextrous innovation, Job autonomy, Unscripted agility, Organizational resilience, Startups, Covid-19 pandemic

Paper type Research paper

\section{Introduction}

Periods of crisis affect organizations and can threaten their survival (Doern, Williams \& Vorley, 2019), and it is not different in the context of Covid-19 (Verma \& Gustafsson, 2020), which broke out in December 2019 in China and was declared a global pandemic in March 2020 (Hua \& Shaw, 2020). Even startups, which permeate innovation and search for quick answers to society's challenges (Spender, Corvello, Grimaldi \& Rippa, 2017), may have their continuity threatened by the pandemic (Kuckertz et al., 2020). Thus, it is necessary that

\footnotetext{
(C) Anderson Betti Frare and Ilse Maria Beuren. Published in Revista de Gestão. Published by Emerald Publishing Limited. This article is published under the Creative Commons Attribution (CC BY 4.0) licence. Anyone may reproduce, distribute, translate and create derivative works of this article (for both commercial and non-commercial purposes), subject to full attribution to the original publication and authors. The full terms of this licence may be seen at http://creativecommons.org/licences/by/4.0/ legalcode

The authors wish to thank the Coordination for the Improvement of Higher Education Personnel (CAPES) - Brazil for financial assistance, Funding Code 001.
}

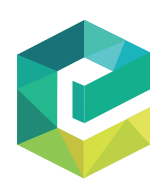

Revista de Gestão Vol. 28 No. 3,2021 Emerald Publishing Limite e-ISSN: $2177-8736$ p-ISSN: $1809-2276$ DOI 10.1108/REGE-01-2021-0005 
REGE 28,3

\section{4}

startups explore ways to continue fostering innovation, to ensure their survival and even to identify new opportunities (Davila, Foster \& Jia, 2010).

Innovation can involve small changes (incremental innovation) and/or disruptive changes (radical innovation) (Benner \& Tushman, 2003). However, managing and promoting ambidextrous innovation is a challenge for organizations (Raisch \& Birkinshaw, 2008; Bedford, Bisbe \& Sweeney, 2019). To this end, job autonomy, in the scope of freedom and latitude of individuals in the organization (Rodríguez, Bravo, Peiró \& Schaufeli, 2001) to conduct and make decisions about their tasks (Cäker \& Siverbo, 2018), can stimulate the creativity of startups' employees and managers (Sauermann, 2018). Organizational resilience becomes useful for organizations to instigate anticipation, endurance and adaptation to a given situation (Duchek, 2020). In this sense, unscripted agility is one of the dimensions of resilience that stands out in periods of crisis and has the potential to leverage innovation (Akgün \& Keskin, 2014).

Evidence suggests that job autonomy can instigate unscripted agility (Hackman \& Oldham, 1976; Cäker \& Siverbo, 2018; Gardner, 2020), and there is a possibility that it is associated with ambidextrous innovation (Akgün \& Keskin, 2014; Hallak, Assaker, O'Connor \& Lee, 2018; Bedford et al., 2019). Also, there is evidence that job autonomy can exert direct and indirect effects on ambidextrous innovation (Rodríguez et al., 2001; Bysted, 2013; Cäker \& Siverbo, 2018). Previous studies that analyzed these constructs individually, in other contexts and types of organizations, reveal a research gap that instigates analyzing them jointly, in the period of the crisis arising from the Covid-19 pandemic, in startups as they have unique dynamics. Thus, the objective of this study is to analyze the influence of job autonomy and unscripted agility on ambidextrous innovation in startups in times of the Covid-19 pandemic.

This research was motivated mainly by the fact that previous studies focus on job autonomy and its relationship with innovation individually (Orth \& Volmer, 2017; AlbortMorant, Ariza-Montes, Leal-Rodríguez \& Giorgi, 2020), which instigates to verify the impact in the organizational innovation sphere, and also by the incipiency of empirical research on building resilience in startups (Haase \& Eberl, 2019). It also instigates exploring relevant antecedents to drive and manage ambidextrous innovation (Bedford et al., 2019), in new contexts and different companies (Buccieri, Javalgi \& Cavusgil, 2020). Lastly, since the e-commerce segment has grown in times of the Covid-19 pandemic (ACI Worldwide, 2020; Forbes, 2020), in part due to the imposition of social distancing (Pejić-Bach, 2021), it is relevant to consider startups in this segment.

In this sense, a survey was conducted with 84 Brazilian startups in the e-commerce, retail and wholesale segments, from a population of 611 organizations registered in the StartupBase database of the Brazilian Startup Association (Abstartups - Associação Brasileira de Startups). Partial least squares structural equation modeling (PLS-SEM) was used to analyze the data, and fuzzy-set qualitative comparative analysis (fsQCA) was used complementarily. The results indicated that unscripted agility has a mediating role in the association of job autonomy and ambidextrous innovation. Furthermore, the findings point to two organizational configurations that lead startups to high ambidextrous innovation.

This study provides theoretical and managerial contributions. In the theoretical context, it intends to demonstrate the possible effects of job autonomy on ambidextrous innovation, highlighting the role of unscripted agility as a possible mediating variable, which is responsible for facilitating this association. In the context of managerial practice, this study may be useful for founders and managers of startups, paving the way for reflections about freedom in conducting tasks (job autonomy) and resilient behavior (unscripted agility), which can leverage from small to more disruptive changes (ambidextrous innovation), especially in times of crisis and uncertainty. 
2. Theoretical framework and hypotheses

\subsection{Job autonomy and unscripted agility}

Job autonomy is a characteristic of managers' work for controlling the performance of their activities (Rodríguez et al., 2001) in a way that the higher the degree of autonomy, the higher the level of freedom in performing their tasks (Hackman \& Oldham, 1976). Job autonomy can produce positive feelings in managers, such as trust (Cäker \& Siverbo, 2018). This autonomy can be beneficial to managers and their organizations in ways that generate various effects, depending on the intensity of the resilience demonstrated (Gardner, 2020). Resilience, in the organizational setting, can represent a meta-capability, consisting of stages of anticipating, enduring and adapting to a given situation (Duchek, 2020). One of the dimensions of organizational resilience concerns original/unscripted agility (Beuren, Santos \& Bernd, 2020), henceforth referred to as unscripted agility. In turbulent contexts, this dimension plays a key role in organizations (Akgün \& Keskin, 2014).

In scenarios with high levels of uncertainty, organizations should encourage the development of resilience competencies (Duchek, 2020). In this perspective, the Covid-19 pandemic context requires organizations to develop resilience to ensure their business continuity (Bryce, Ring, Ashby \& Wardman, 2020). It is recognized that crises directly affect organizations. However, the effect varies depending on their capabilities and resources (Doern et al., 2019). Startups are apparently exposed to failure or success faster than ever before (Salamzadeh \& Dana, 2020), which may indicate distinct degrees of organizational resilience and, particularly, unscripted agility (Akgün \& Keskin, 2014).

Organizational behaviors of agility and re-adaptation have the potential to promote higher levels of resilience (Kantur \& Iseri-Say, 2012) so as to instigate the rapid recognition of opportunities and new directions for conducting business (McCann, 2004). Thus, it is assumed that one of the organizational behaviors that can foster unscripted agility is job autonomy since greater freedom and latitude for employees to perform their tasks can instigate new ways and unscripted agility to face the uncertainties stemming from the Covid-19 pandemic. Given these arguments, the following hypothesis was formulated:

H1(+). Job autonomy has a direct and positive effect on unscripted agility.

\subsection{Unscripted agility and ambidextrous innovation}

Organizations increasingly need to implement strategies that promote ambidextrous innovation in order to provide for the management of tensions and contradictory goals (Birkinshaw \& Gupta, 2013). Ambidextrous innovation is simultaneously explored in opposing biases: incremental innovation and radical innovation (Raisch \& Birkinshaw, 2008). Incremental innovations involve minor readjustments and improvements, whereas radical innovations involve disruptive changes (Benner \& Tushman, 2003).

When organizations make modifications to their products and/or services in both incremental and radical ways, it results in ambidextrous innovation (Sarkees \& Hulland, 2009). Previous studies emphasize the pertinence of analyzing ambidextrous innovation in organizations considering the dimensions of incremental and radical innovation simultaneously (Bedford et al., 2019; Monteiro \& Beuren, 2020). Ambidextrous innovation is crucial for the survival of organizations in dynamic scenarios with market competition, turbulence and uncertainty (Harmancioglu \& Sääksjä). In these scenarios, innovation is an essential element for successful entrepreneurship (Devece, Peris-Ortiz \& RuedaArmengot, 2016).

Startups have innovation at their core, from new ideas, products, services and processes that can speed up/solve a diversity of problems and contexts (Spender et al., 2017). Despite being vulnerable to the impacts of the crisis caused by the Covid-19 pandemic (Kuckertz et al., 2020), they can show outstanding survivability and responsiveness. However, organizational
Brazilian startups in Covid-19 crisis 
REGE 28,3

\section{6}

resilience is crucial for them to readapt and remain in the market (Doern et al., 2019). Promoting innovation in times of turbulence permeates unscripted agility (Akgün \& Keskin, 2014), as in the Covid-19 pandemic crisis, given the demand for quick and agile solutions, especially in startups that already have the continuous challenge of innovating (Kuckertz et al., 2020).

Resilience is important for managing adversity, especially for promoting innovation (Hallak, Assaker, O'Connor, \& Lee, 2018). When facing the opportunities that may arise in periods of crisis (Doern et al., 2019), unscripted agility is a determinant of innovation (Akgün $\&$ Keskin, 2014) so as to act as a facilitating means for a variety of innovations to take place, especially in the technological context (Diamond, 1996). Just as the other managerial characteristics are important antecedents of ambidextrous innovation (Bedford et al., 2019), it is assumed that unscripted agility may be pertinent. From this perspective, the following hypothesis is formulated:

H2(+). Unscripted agility has a direct and positive effect on ambidextrous innovation.

\subsection{Effects of job autonomy on ambidextrous innovation}

The positive effect of job autonomy on employees' innovative behavior is supported by the literature (Orth \& Volmer, 2017; Albort-Morant et al., 2020). However, the findings on the impact of job autonomy on organizational innovation or ambidextrous innovation are not conclusive. Evidence shows that job autonomy allows for flexible time and opportunities to perform the activities (Cäker \& Siverbo, 2018), which may interfere with how startups' managers and employees plan, conduct and make decisions (Rodríguez et al., 2001). This freedom can stimulate the creation of new ideas and innovative solutions (Bysted, 2013).

As instigating innovation is at the core of the startups, not only the founders and managers tend to exhibit creative behaviors, but also the employees (Sauermann, 2018). Thus, it is assumed the coexistence of an environment conducive to innovation, which can be driven by job autonomy (Bysted, 2013). It is argued that the level of freedom and latitude given to the organizational members can directly reflect on the incremental and radical innovations (ambidextrous innovation) of startups in the Covid-19 pandemic context, which demands even more from these companies (Kuckertz et al., 2020). Thus, it is assumed that:

$H 3 a(+)$. Job autonomy has a direct and positive effect on ambidextrous innovation.

In addition to expecting a direct and positive effect of job autonomy on ambidextrous innovation, evidence suggests an indirect and positive effect through unscripted agility. Evidence suggests that job autonomy favors organizational resilience within the scope of unscripted agility (Hackman \& Oldham, 1976; Cäker \& Siverbo, 2018; Gardner, 2020), in addition to the likelihood of leveraging ambidextrous innovation (Diamond, 1996; Akgün \& Keskin, 2014; Hallak et al., 2018; Bedford et al., 2019). Thus, it is assumed that unscripted agility exerts an effect between job autonomy and ambidextrous innovation, that unscripted agility can act as a mediating variable between job autonomy and ambidextrous innovation, as per the following hypothesis:

$H 3 b(+)$. Job autonomy exerts indirect and positive effect on ambidextrous innovation through unscripted agility.

In line with the theoretical framework and the hypotheses proposed, the conceptual model (Figure 1) to be instrumentalized in this research was elaborated.

Two control variables (external financing and institutional ties) were added to the model. 


\section{Method}

\subsection{Population and context of the research}

The research population consists of startups in the e-commerce, retail and wholesale segments registered in the StartupBase. The Brazilian Association of Startups (Abstartups Associação Brasileira de Startups) describes a startup as "a company that is born from an agile and concise business model, able to generate value for its customer by solving a real problem of the real world" (Abstartups, 2021). It also highlights that startups essentially use technologies to promote a scalable business solution. This characterization is in line with Blank \& Dorf (2012), who conceptualize startups as organizations that seek a repeatable and scalable business model. The herein study is based on these conceptions of startups.

The Covid-19 pandemic has boosted the volume of e-commerce transactions globally (ACI Worldwide, 2020), including the Brazilian market (Forbes, 2020). Brazil is considered a country that fosters and instigates the development of technology-based startups (Gavasa, 2018), which facilitates the conception and market share of this type of organization. In parallel, startups are characterized by presenting innovative solutions (Hunt, 2013) and responses to unforeseen and sudden challenges, as in the case of the restrictions and changes derived from the Covid-19 pandemic (Kuckertz et al., 2020). The innovation potential of Brazilian startups is observed in the context of e-commerce, retail and wholesale, in the face of the changes that occurred due to the Covid-19 pandemic.

The research was conducted through the use of a survey applied to founders/managers of e-commerce, retail and wholesale startups. Abstartups maintains a database, called StartupBase, in which 611 e-commerce, retail and wholesale startups that are supposedly in operation are listed (StartupBase, 2020). Thus, the 611 startups were invited to participate and make up the research population.

\subsection{Research instrument and data collection}

The research instrument consists of a cover letter and Informed Consent Form (ICF), latent constructs and their indicators, and demographic questions. In the cover letter, strategies were adopted to minimize the common method bias (CMB), which is inherent to selfcompletion surveys and the respondents answer both the dependent and independent variables (Podsakoff \& Organ, 1986). The strategies consisted of making the research objectives explicit, ensuring anonymity and emphasizing that there are no right or wrong answers (Podsakoff, MacKenzie, Lee \& Podsakoff, 2003). ICF provided for the respondent's agreement is used to participate in the survey and authorize the use of the data for academic purposes.

A five-point Likert scale was used to measure the latent constructs and indicators. In order to minimize the $\mathrm{CMB}$, different weightings were used for the scale points, depending on the construct (Podsakoff et al., 2003). The construct job autonomy (three items) was adapted from Rodríguez et al. (2001), and Cäker \& Siverbo (2018), with an accuracy-weighted scale (1 = not

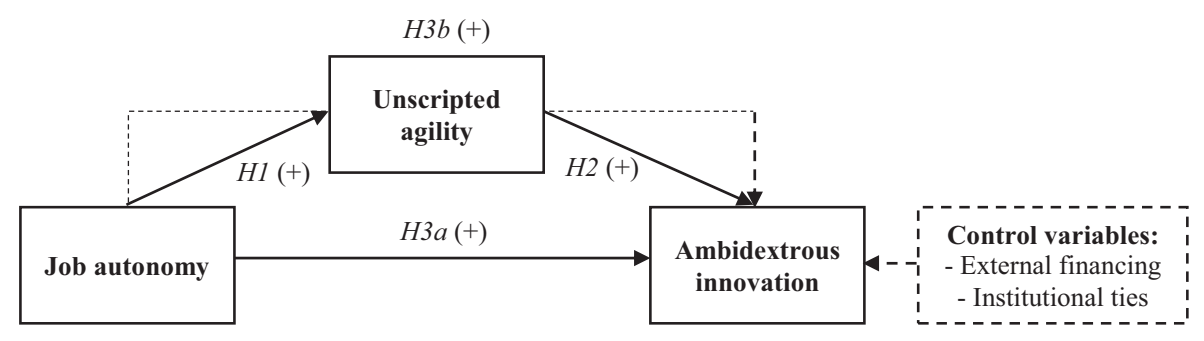

Brazilian startups in Covid-19 crisis

\section{.}


REGE 28,3 accurate and $5=$ totally accurate). The unscripted agility variable (five items) was adapted from Akgün \& Keskin (2014) and Beuren \& Santos (2019), with an agreement scale ( 1 = strongly disagree and $5=$ strongly agree).

Ambidextrous innovation was measured as a second-order construct, which is composed of two first-order dimensions: incremental innovation (three items) and radical innovation (three items). Both were adapted from Atuahene-Gima (2005), Lin, McDonough, Lin \& Lin (2013), and Bedford et al. (2019), on an agreement scale (1 = strongly disagree and $5=$ strongly agree). Similar to Monteiro \& Beuren (2020), respondents were asked to indicate to what extent the startup introduced new incremental products/services during the pandemic period, and to what extent it more radically introduced new products/services during the pandemic period compared to their main competitors. Considering it as a construct that encompasses the dimensions of incremental and radical innovation, ambidextrous innovation is in accordance with previous literature (Bedford et al., 2019; Monteiro \& Beuren, 2020).

Two binary control variables (no/yes) were included in the research: external financing, in case the startup received or is receiving financial resources from third parties; and institutional ties, in case the startup has ties with accelerators, incubators, technology parks or similar. External financing can be a key factor for survival and growth (Davila et al., 2015), and when they have institutional ties, startups connected with innovative environments tend to denote differentiated forms of support and conditions to develop competencies that ensure their survival (Vargas \& Plonski, 2019).

The survey was instrumentalized in the QuestionPro® platform and the link to it was sent to the founders/managers of the startups through the social network LinkedIn ${ }^{\circledR}$, from June to August 2020. A total of 84 startups (13.75\% of the population) submitted their responses, making up the final sample. Regarding the profile of the respondents, $70.24 \%$ are founders (individual owner or partner), have been at the startup for an average of 2 to 3 years, are in average 37 years old, and $51.19 \%$ have a post-graduation degree in specialization, Master of Business Administration (MBA) or master's degree. Regarding the profile of the startups, $60.71 \%(n=51)$ raised or are raising external financing, and $42.86 \%(n=36)$ have institutional ties with an accelerator, incubator, technology park or the like.

\subsection{Data analysis techniques}

A post hoc test was elaborated in the $\mathrm{G}^{*}$ Power 3 software with an average effect size $\left(f^{2}\right)(0.15)$, error probability $(\alpha)$ of $5 \%$, a sample of 84 respondents and 4 predictors in the dependent variable (ambidextrous innovation), obtaining a satisfactory statistical power (Ringle, Silva $\&$ Bido, 2014). The sample size is satisfactorily aligned with related studies that used such a technique (Garidis \& Rossmann, 2019; Theiss \& Beuren, 2020). Thus, the sample size is adequate for applying PLS-SEM.

PLS-SEM has been receiving attention and being widely employed in management accounting (Nitzl, 2016) and entrepreneurship (Manley, Hair, Williams \& McDowell, 2020) research. Some reasons for its acceptability in the field of business and management are its pertinence for complex modeling, for relatively limited sample sizes, for samples with an absence of multivariate normality of the data, analyses of relationships with a more exploratory character and the possibility of incremental analyses (Hair, Risher, Sarstedt, \& Ringle, 2019). Furthermore, related studies that have conducted surveys contemplating constructs based on multi-item, captured in Likert scales, used PLS-SEM (e.g. Beuren \& Santos, 2019; Kaya, Abubakar, Behravesh, Yildiz \& Mert, 2020; Theiss \& Beuren, 2020; Crespo, Curado, Oliveira \& Muñoz-Pascual, 2021). 
One of the key points for choosing PLS-SEM consists in the absence of normal data, which commonly occurs in social science studies (Nitzl, 2016). From the perspective of non-normal data and small sample sizes, covariance-based structural equation modeling (CB-SEM) may have not so adequate results (Reinartz, Haenlein \& Henseler, 2009), while PLS-SEM is more appropriate in such cases (Sarstedt, Hair, Ringle, Thiele \& Gudergan, 2016; Hair et al., 2019). The study employs mediation analysis, in which the independent variable (job autonomy) is expected to exert an indirect effect on the dependent variable (ambidextrous innovation) through a third variable (unscripted agility) (Bido \& Silva, 2019). PLS-SEM was instrumentalized in the software SmartPLS 3 (Ringle, Wende \& Becker, 2015).

An asymmetric analysis (fsQCA) was performed to complement the symmetric analysis (PLS-SEM). This technique permeates the analysis of necessary conditions and combinations of these conditions that may be sufficient to promote the success of the dependent variable (Ragin, 2008), in this case, high ambidextrous innovation. The fsQCA is receiving prominence in entrepreneurship and innovation research (Kraus, Ribeiro-Soriano \& Schüssler 2018), also proving useful in the context of managerial accounting (Bedford, Malmi \& Sandelin, 2016). This technique was instrumentalized in the software fsQCA 3.0. The use of PLS-SEM and fsQCA provides complementary and relevant results (Kaya et al., 2020; Crespo et al., 2021).

\subsection{Common method bias and non-response bias}

In addition to the care taken to minimize $\mathrm{CMB}$, tests were conducted to check for the possible presence of this problem (Podsakoff et al., 2003). Harman's single factor test was conducted through exploratory factor analysis (EFA), where the first factor resulted in $33.80 \%$ of the total variance explained, below the $50 \%$ threshold (Podsakoff et al., 2003), indicating that the $\mathrm{CMB}$ is not a problem. Since the demographic characteristics of nonrespondents are not known, the first-last criterion was adopted to analyze the non-response bias, in an analogy that the last respondents show similar behaviors to the non-respondents (Mahama \& Cheng, 2013). Thus, a test of means was conducted between the first $25 \%$ and last $25 \%$ respondents, and the constructs showed no significant differences ( $p$-values between 0.305 and 0.725$)$, suggesting that the responses are congruent regardless of the timing of the response.

\section{Data analysis}

\subsection{PLS-SEM analysis}

Higher-order constructs are useful for modeling variables with higher levels of abstraction (Sarstedt, Hair, Cheah, Becker \& Ringle, 2019). Therefore, in addition to the single-order constructs (job autonomy and unscripted agility), a second-order construct (ambidextrous innovation) was used, composed of two first-order constructs (incremental innovation and radical innovation). To this end, a reflective-reflective second-order construct was adopted (Sarstedt et al., 2019). Table 1 presents the reliability, validity and other assumptions, for the unique order and second-order constructs and control variables.

The factor loadings were all above 0.7 and rated in their respective construct, which indicates adequacy (Hair, Hult, Ringle \& Sarstedt, 2016). For internal consistency, the values of Cronbach's Alpha $(\alpha)$, Dijkstra-Henseler's Rho $\left(\rho_{A}\right)$ and Composite reliability $(\mathrm{CR})$ ranged from 0.7 to 0.95 , which indicates its adequacy (Hair et al., 2019). Convergent validity is evidenced by the average variance extracted (AVE), with values above 0.5 (Hair et al., 2019). Discriminant validity was verified by the Fornell-Larcker criterion, with the square root of the AVE (italic values in the diagonal row) greater than the correlation of the construct with the others (Hair et al., 2016), and by the values of heterotrait-monotrait ratio of correlations (HTMT) below 0.85 (Hair et al., 2019).

\section{Brazilian startups in} Covid-19 crisis 
REGE 28,3

\section{0}

Table 1.

Measurement model

\begin{tabular}{lcccccccccc}
\hline & \multicolumn{4}{c}{ Reliability and validity } & \multicolumn{5}{c}{ Fornell-LarckerHTMT } \\
Constructs & $\alpha$ & $\rho_{A}$ & \multicolumn{1}{c}{ CR } & AVE & 1 & \multicolumn{1}{c}{2} & 3 & \multicolumn{1}{c}{4} & 5 \\
\hline 1. Job autonomy & 0.775 & 0.784 & 0.869 & 0.690 & 0.831 & 0.442 & 0.130 & 0.095 & 0.141 \\
2. Unscripted agility & 0.813 & 0.816 & 0.869 & 0.571 & 0.364 & 0.756 & 0.561 & 0.147 & 0.097 \\
3. Ambidextrous innovation & 0.907 & 0.911 & 0.920 & 0.851 & 0.076 & 0.490 & 0.922 & 0.067 & 0.055 \\
4. External financing & - & - & - & - & -0.089 & -0.124 & 0.027 & - & 0.204 \\
5. Institutional ties & - & - & - & - & 0.059 & 0.076 & 0.036 & 0.204 & -
\end{tabular}

Note(s): the values in the left-bottom diagonal refer to the Fornell-Larcker criterion, the ones in the upperright diagonal refer to the HTMT criterion and those in italic are the AVE square root of the respective construct

The structural model (Table 2) used the bootstrap model to calculate the significance, calculated the $95 \%$ confidence interval (CI) through the bias-correct and accelerated bootstrap (BCa) method, and two-tailed test and resample of 5,000 (Hair et al., 2016).

Initially, attention was paid to the possible presence of multicollinearity. The internal variance inflation factor (VIF) (of the constructs) showed values below 3 (from 1 to 1.158), indicating the absence of this problem (Hair et al., 2019). About the explained variance of the endogenous variables, the coefficient of determination $\left(R^{2}\right)$ for unscripted agility $(12.2 \%)$ is close to medium $(13 \%)$, while for ambidextrous innovation $(22.1 \%)$ is close to large $(26 \%)$ (Cohen, 1988). In turn, the Stone-Geisser indicator $\left(Q^{2}\right)$ was used to calculate the predictive relevance of the model, indicating small $(0 \%)$ to medium $(25 \%)$ predictive accuracy for unscripted agility (5.3\%) and ambidextrous innovation (14.1\%) (Hair et al., 2019). The control variables show no significant association with ambidextrous innovation.

\section{2 $f_{S} Q C A$ analysis}

The asymmetric fsQCA analysis requires a logical sequence of procedures. First, the fuzzification is conducted in order to convert the mean values of the constructs into fuzzy sets, with values between 0 and 1 (Ragin, 2008). To do so, three qualitative anchors should be defined: full membership (0.95), crossover point (0.50) and full non-membership (0.05) (Ragin, 2008). For the five-point Likert scale constructs (job autonomy, unscripted agility and ambidextrous innovation), the anchors were set at 4, 3 and 2 (Su, Zhang \& Ma, 2019). For the binary variables (external financing and institutional ties), the values are calibrated as crisp sets, with 0 for absence and 1 for the presence of such a situation or characteristic (Ragin, 1987).

Next, the necessary conditions for the success of the dependent variable, in this case, ambidextrous innovation, are analyzed. A condition can be necessary (consistency above 0.90), almost always necessary (consistency between 0.80 and 0.90) or not necessary (consistency below 0.80) (Ragin, 2000). In the analysis of necessary conditions, it can be seen

\begin{tabular}{llrccc}
\hline $\mathrm{H}$ & Relationship & Beta $(\beta)$ & $t$-value & $p$-value & CI [95\%] \\
\hline $\mathrm{H} 1$ & Job autonomy $\rightarrow$ unscripted agility & 0.364 & 2.367 & $0.018^{*}$ & {$[0.019 ; 0.599]$} \\
$\mathrm{H} 2$ & Unscripted agility $\rightarrow$ ambidextrous innovation & 0.543 & 4.797 & $0.000^{* *}$ & {$[0.310 ; 0.734]$} \\
$\mathrm{H} 3 \mathrm{a}$ & Job autonomy $\rightarrow$ ambidextrous innovation & -0.112 & 0.815 & 0.415 & {$[-0.364 ; 0.174]$} \\
$\mathrm{H} 3 \mathrm{~b}$ & Job autonomy $\rightarrow$ unscripted agility $\rightarrow$ ambidextrous & 0.198 & 2.141 & $0.032^{*}$ & {$[0.003 ; 0.373]$} \\
& innovation & & & & \\
- & External financing $\rightarrow$ ambidextrous innovation & 0.088 & 0.897 & 0.370 & {$[-0.092 ; 0.289]$} \\
- & Institutional ties $\rightarrow$ ambidextrous innovation & -0.017 & 0.170 & 0.865 & {$[-0.209 ; 0.181]$}
\end{tabular}

Structural model

Note(s): $* p<0.05 ; * * p<0.01$ 
that job autonomy (0.967) is necessary and unscripted agility (0.886) is almost always necessary for promoting high ambidextrous innovation. The other conditions are not necessary when observed individually.

The last step of the fsQCA requires the creation of a truth table ( $2^{k}$ rows), where $k$ is the number of causal conditions that can promote the success of the dependent variable (Ragin, 2008). After creating the truth table, a consistency threshold of 0.80 is set, as suggested by Ragin (2008). The parsimonious and intermediate solutions were considered together, with the conditions that are part of both (parsimonious and intermediate) being classified as core conditions, while those that appear only in the intermediate solution as peripheral conditions (Fiss, 2011). Two rows (solutions) meet the consistency threshold (Table 3).

The consistency for each solution and overall of the model exceeds the threshold of 0.80 , demonstrating adequacy regarding the relevance of the solutions (Ragin, 2008). Coverage refers to the proportion of cases (startups) that use a given strategy (solution) to promote high ambidextrous innovation. In this sense, unique coverage represents the proportion of cases covered exclusively by a given solution; raw coverage indicates the proportion of cases covered, together with the other possible conditions; and the overall coverage shows the total proportion of cases that uses any of the two solutions (Ragin, 2008). Broadly speaking, coverage can be compared to the $R^{2}$ of regression techniques (Woodside, 2013).

Thus, Solution 2 presents the highest raw coverage (35.3\% of the cases) and is constituted by the presence of all conditions, with unscripted agility, external financing and institutional ties being core conditions, while job autonomy is a peripheral condition. This finding highlights the relevance of this set of antecedents for the promotion of high ambidextrous innovation. Solution 1 represents $4.1 \%$ of the cases and reinforces that the presence of unscripted agility is a core condition. However, at the expense of the absence of external financing and institutional ties, it is postulated that working autonomy must be an absent condition in order for the cases covered by the solution to achieve success.

\subsection{Discussion of the results}

H1 proposes that job autonomy has a direct and positive effect on the unscripted agility of startups in times of the Covid-19 pandemic, and it had support for acceptance $(\beta=0.364$, $p<0.05)$. It is inferred that the organizational behavior of instigating freedom, for the body of the organization to take control and plan tasks, has the potential to promote higher levels of organizational resilience (Kantur \& Iseri-Say, 2012), as well as boosting unscripted agility (Akgün \& Keskin, 2014). In times of the Covid-19 pandemic, startups are meeting the

\begin{tabular}{|c|c|c|}
\hline \multirow[b]{2}{*}{ Variables } & \multicolumn{2}{|c|}{ Solutions for high ambidextrous innovation } \\
\hline & Solution 1 & Solution 2 \\
\hline Unscripted agility & - & • \\
\hline Job autonomy & 0 & • \\
\hline External financing & o & - \\
\hline Institutional ties & o & - \\
\hline Raw coverage & 0.041 & 0.353 \\
\hline Unique coverage & 0.017 & 0.330 \\
\hline Consistency & 0.949 & 0.830 \\
\hline Overall coverage & & \\
\hline Overall consistency & & \\
\hline
\end{tabular}

Note(s): Black circles $(\mathbf{O})$ indicate the presence of the condition and white circles $(\bigcirc)$ the absence of the condition

Large circles indicate core conditions and small circles peripheral conditions
Brazilian startups in Covid-19 crisis

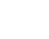


REGE 28,3 important goal of promoting organizational resilience (Duchek, 2020), essential to their survival (Bryce et al., 2020) and possible recognition of new opportunities (McCann, 2004).

$\mathrm{H} 2$ proposed that unscripted agility has a direct and positive effect on ambidextrous innovation of startups in times of the Covid-19 pandemic, and it cannot be rejected $(\beta=0.543$, $p<0.01$ ). According to the fsQCA, unscripted agility is an almost always necessary condition (consistency $=0.886$ ), but not sufficient on its own. From this perspective, unscripted agility is configured as a core condition in the two sufficient solutions for promoting high ambidextrous innovation.

The statistical supports denote the multiple facets of organizational resilience, in the form of unscripted agility, to promote ambidextrous innovation (incremental and radical) in startups in the context of the crisis caused by the Covid-19 pandemic. This finding is supported by the evidence from previous studies (Diamond, 1996; Akgün \& Keskin, 2014; Hallak et al., 2018) that resilient behaviors drive innovation, also in crisis contexts. The innovative profile of startups (Spender et al., 2017), combined with the unscripted agility (Akgün \& Keskin, 2014), in times of crisis (Doern et al., 2019), proves to be a pertinent predictor for the creation of incremental and radical innovations.

H3a postulates that job autonomy has a direct and positive effect on startups' unscripted agility in times of the Covid-19 pandemic, but it was not supported $(\beta=-0.112, p>0.10)$. While the literature on job autonomy highlights its impact on individual innovative behavior (Orth \& Volmer, 2017; Albort-Morant et al., 2020), the impact on organizational innovation or ambidextrous innovation is not evident. Although job autonomy instigates flexibility of time, routines, and opportunities (Cäker \& Siverbo, 2018) and possibly planning and conducting tasks (Rodríguez et al., 2001), no statistical support was obtained to argue that this autonomy is associated with ambidextrous innovation, at least not directly.

H3bpostulates that through unscripted agility, job autonomy exerts an indirect and positive effect on startups' ambidextrous innovation in times of the Covid-19 pandemic cannot be rejected $(\beta=0.198, p<0.05)$. Since the direct association is not significant, there is full mediation (Bido \& Silva, 2019), i.e. unscripted agility exhibits full mediating effect between job autonomy and ambidextrous innovation.

In fsQCA, job autonomy is conditioned as a variable that is always necessary, but not sufficient on its own. When its presence is combined (Solution 2) with the presence of unscripted agility, external financing and institutional ties, it promotes high ambidextrous innovation (35.3\% of cases). However, when combined with the absence of external financing and institutional ties (Solution 1), it also becomes a condition that needs to be absent for high ambidextrous innovation to occur (4.1\% of cases). Given the larger scope of cases in Solution 2, it suggests that the third-party financing represents a crucial factor, as well as having some ties since ambidextrous innovation can be favored by the ecosystem, the training received, the innovative environment and the availability of the local resource (Vargas \& Plonski, 2019).

As evidenced in the third set of hypotheses, although there is no direct effect of job autonomy on ambidextrous innovation, there is an indirect effect, through unscripted agility. The fsQCA evidences that job autonomy, when combined with other variables, has the potential to promote high ambidextrous innovation, i.e. it takes on the asymmetric perspective. Thus, it indicates the respective symmetric impact of job autonomy on unscripted agility (Hackman \& Oldham, 1976; Cäker \& Siverbo, 2018; Gardner, 2020) and of unscripted agility on innovation (Diamond, 1996; Akgün \& Keskin, 2014; Hallak et al., 2018).

\section{Final considerations}

\subsection{Conclusions}

The results of the research lead to the conclusion that job autonomy and organizational resilience, in the unscripted agility dimension, are important drivers of startups' 
ambidextrous innovation (incremental and radical) in times of the Covid-19 pandemic. It was noticed that unscripted agility plays an important role in translating and passing on the role of job autonomy in favor of ambidextrous innovation. Moreover, two configurations between job autonomy, unscripted agility, external financing and institutional ties promote high ambidextrous innovation. The presence of these four elements together is the main pathway the sample relies on to achieve high ambidextrous innovation. Overall, the findings point to organizational behaviors that startups in the e-commerce segment rely on during the pandemic to promote an incremental and radical product and service innovation and pursue opportunities and business continuity.

\subsection{Implications}

One of the implications of this study is that it contributes to research that seeks to understand the mechanisms that are positively associated with ambidextrous innovation (Bedford et al., 2019; Monteiro \& Beuren, 2020) by adding job autonomy and unscripted agility into the discussion. Another implication is that it adds new evidence for the innovation behavior of startups in pandemic times (Kuckertz et al., 2020), considering a specific segment (e-commerce). In addition to understanding the challenges faced by startups in the pandemic (Salamzadeh \& Dana, 2020), the study explores elements that are associated with innovation and that may help the survival and continuity of the business. Also, it adds new evidence to entrepreneurship in times of crisis (Devece et al., 2016).

This study also offers contributions to the debates on building resilience in startups (Haase \& Eberl, 2019), adding evidence on how unscripted agility assumes a pertinent role in startups during times of disruptions, crises and pandemics. Its mediating role between job autonomy and innovation ambidexterity is highlighted. It also provides new evidence on the role of external financing (Davila et al., 2015) and institutional support (Vargas \& Plonski, 2019) in the survival of startups, in particular for them to achieve high ambidextrous product and service innovation. Overall, the study contributes to the literature by discussing elements that are associated with ambidextrous innovation, exploring innovation in startups in times of crisis, specifically in times of the Covid-19 pandemic and contemplating the role of resilience in startups.

Regarding managerial practice, this study can provide informational subsidies to startups' founders and managers. First, it demonstrates how the freedom and latitude attributed to the members of the organization (job autonomy) can stimulate creativity and the emergence of new ideas, which, despite not directly driving incremental and radical innovations (ambidextrous innovation), through resilience (unscripted agility), was proven to have an indirect effect. Furthermore, it lists paths for startups to promote high ambidextrous innovation, considering the possible conditions of external financing and institutional ties with some entrepreneurial ecosystem. In summary, the study presents startups' founders and managers with ways to promote incremental and radical innovations, through autonomy and resilience, in a singular period of crisis.

\subsection{Limitations and suggestions}

The findings of the research have limitations inherent to the study. They contemplate exclusively e-commerce, retail and wholesale startups. Therefore, the expansion to other segments should be parsimonious. The sample does not have a probabilistic nature, which does not allow extrapolation of the findings, while at the same time providing opportunities for new research in other contexts and probabilistic samples. The low representativeness of the sample in relation to the population ( $13.75 \%$ ) is a limiting factor, despite being consistent with response rates of similar studies (Samagaio, Crespo \& Rodrigues, 2018; Balboni, Bortoluzzi, Pugliese \& Tracogna, 2019). Also, the cross-sectional study limits the inferential power of the findings.

\section{Brazilian startups in Covid-19 crisis}


REGE 28,3

\section{4}

Only two control variables were used; in the scope of external financing no cash was considered; and regarding the external ties, no distinction was made between accelerators, incubators, technology parks or the like. Although the study considered these control variables, due to the heterogeneity observed and because of the sample size, the analysis of possible unobserved heterogeneities through finite mixture partial least squares was not performed. These limitations, however, may pose new research opportunities.

\section{References}

ACI Worldwide (2020). ACI Worldwide research reveals increase in June eCommerce sales - largest since the start of COVID-19 pandemic restrictions, Recuperado em 20 ago., 2020, de, available at: https:/www.aciworldwide.com/news-and-events/press-releases/2020/july/global-ecommercesales-rise-28-percent-in-june-aci-worldwide-research-reveals.

Akgün, A.E., \& Keskin, H. (2014). Organisational resilience capacity and firm product innovativeness and performance. International Journal of Production Research, 52(23), 6918-6937, doi: 10.1080/ 00207543.2014.910624.

Albort-Morant, G., Ariza-Montes, A., Leal-Rodríguez, A., \& Giorgi, G. (2020). How does positive workrelated stress affect the degree of innovation development?. International Journal of Environmental Research and Public Health, 17(2), 1-15, doi: 10.3390/ijerph17020520.

Associação Brasileira de Startups (Abstartups) (2021). Mas afinal, o que são startups?, Recuperado em 17 fev., 2021, de, available at: https://abstartups.com.br/definicao-startups/.

Atuahene-Gima, K. (2005). Resolving the capability-rigidity paradox in new product innovation. Journal of Marketing, 69(4), 61-83, doi: 10.1509/jmkg.2005.69.4.61.

Balboni, B., Bortoluzzi, G., Pugliese, R., \& Tracogna, A. (2019). Business model evolution, contextual ambidexterity and the growth performance of high-tech start-ups. Journal of Business Research, 99, 115-124, doi: 10.1016/j.jbusres.2019.02.029.

Bedford, D.S., Malmi, T., \& Sandelin, M. (2016). Management control effectiveness and strategy: An empirical analysis of packages and systems. Accounting, Organizations and Society, 51, 12-28, doi: 10.1016/j.aos.2016.04.002.

Bedford, D.S., Bisbe, J., \& Sweeney, B. (2019). Performance measurement systems as generators of cognitive conflict in ambidextrous firms. Accounting, Organizations and Society, 72, 21-37, doi: 10.1016/j.aos.2018.05.010.

Benner, M.J., \& Tushman, M.L. (2003). Exploitation, exploration, and process management: The productivity dilemma revisited. Academy of Management Review, 28(2), 238-256, doi: 10.5465/ amr.2003.9416096.

Beuren, I.M., \& Santos, V.D. (2019). Sistemas de controle gerencial habilitantes e coercitivos e resiliência organizacional. Revista Contabilidade and Finanças, 30(81), 307-323, doi: 10.1590/ 1808-057x201908210.

Beuren, I.M., Santos, V.D., \& Bernd, D.C. (2020). Efeitos do Sistema de Controle Gerencial no Empowerment e na Resiliência Organizacional. BBR-Brazilian Business Review, 17(2), 211-232, doi: 10.15728/bbr.2020.17.2.5.

Bido, D.S., \& Silva, D. (2019). SmartPLS 3: Especificação, estimação, avaliação e relato. Administração: Ensino e Pesquisa, 20(2), 1-31, doi: 10.13058/raep.2019.v20n2.1545.

Birkinshaw, J., \& Gupta, K. (2013). Clarifying the distinctive contribution of ambidexterity to the field of organization studies. Academy of Management Perspectives, 27(4), 287-298, doi: 10.5465/amp. 2012.0167.

Blank, S., \& Dorf, B. (2012). The Startup Owner's Manual: The Step-by-step Guide for Building a Great Company. Pennsauken, New Jersey, NJ: BookBaby.

Bryce, C., Ring, P., Ashby, S., \& Wardman, J. K. (2020). Resilience in the face of uncertainty: Early lessons from the COVID-19 pandemic. Journal of Risk Research, 9(7-8), 1-8, doi: 10.1080/13669877.2020. 1756379. 
Buccieri, D., Javalgi, R. G., \& Cavusgil, E. (2020). International new venture performance: Role of international entrepreneurial culture, ambidextrous innovation, and dynamic marketing capabilities. International Business Review, 29(2), 1-15, 101639, doi: 10.1016/j.ibusrev.2019. 101639 .

Bysted, R. (2013). Innovative employee behaviour. The moderating effects of mental involvement and job satisfaction on contextual variables. European Journal of Innovation Management, 16(3), 268-284, doi: 10.1108/EJIM-09-2011-0069.

Cäker, M., \& Siverbo, S. (2018). Effects of performance measurement system inconsistency on managers' role clarity and well-being. Scandinavian Journal of Management, 34(3), 256-266, doi: 10.1016/j.scaman.2018.06.005.

Cohen, J. (1988). Statistical Power Analysis for the Behavioral Sciences. Mahwah: Lawrence Erlbaum Associates.

Crespo, N.F., Curado, C., Oliveira, M., \& Muñoz-Pascual, L. (2021). Entrepreneurial capital leveraging innovation in micro firms: A mixed-methods perspective. Journal of Business Research, 123, 333-342, doi: 10.1016/j.jbusres.2020.10.001.

Davila, A., Foster, G., \& Jia, N. (2010). Building sustainable high-growth startup companies: Management systems as an accelerator. California Management Review, 52(3), 79-105.

Davila, A., Foster, G., \& Jia, N. (2015). The valuation of management control systems in startup companies: International field-based evidence. European Accounting Review, 24(2), 207-239, doi: 10.1080/09638180.2014.965720.

Devece, C., Peris-Ortiz, M., \& Rueda-Armengot, C. (2016). Entrepreneurship during economic crisis: Success factors and paths to failure. Journal of Business Research, 69(11), 5366-5370, doi: 10. 1016/j.jbusres.2016.04.139.

Diamond, M.A. (1996). Innovation and diffusion of technology: A human process. Consulting Psychology Journal: Practice and Research, 48(4), 221-229, doi: 10.1037/1061-4087.48.4.221.

Doern, R., Williams, N., \& Vorley, T. (2019). Special issue on entrepreneurship and crises: Business as usual? An introduction and review of the literature. Entrepreneurship and Regional Development, 31(5-6), 400-412, doi: 10.1080/08985626.2018.1541590.

Duchek, S. (2020). Organizational resilience: A capability-based conceptualization. Business Research, 13(1), 215-246, doi: 10.1007/s40685-019-0085-7.

Fiss, P.C. (2011). Building better causal theories: A fuzzy set approach to typologies in organization research. Academy of Management Journal, 54(2), 393-420, doi: 10.5465/amj.2011.60263120.

Forbes (2020). Com Covid-19, e-commerce já é 48\% maior que no mesmo período de 2019, Recuperado em 17 ago., 2020, de, available at: https://forbes.com.br/colunas/2020/05/com-covid-19-ecommerce-ja-e-48-maior-que-no-mesmo-periodo-de-2019/.

Gardner, D.G. (2020). The importance of being resilient: Psychological well-being, job autonomy, and self-esteem of organization managers. Personality and Individual Differences, 155, 109731, doi: 10.1016/j.paid.2019.109731.

Garidis, K., \& Rossmann, A. (2019). A framework for cooperation behavior of start-ups: Developing a multi-item scale and its performance impacts. Journal of Small Business and Enterprise Development, 26(6/7), 877-890, doi: 10.1108/JSBED-04-2019-0125.

Gavasa, J. (2018). Best cities to create a startup in Latin America, Recuperado em 22 ago., 2020, de, available at: https://panamericanworld.com/en/magazine/startups/best-cities-to-create-a-startupin-latin-america/.

Haase, A., \& Eberl, P. (2019). The challenges of routinizing for building resilient startups. Journal of Small Business Management, 57(sup 2), 579-597, doi: 10.1111/jsbm.12511.

Hackman, J.R., \& Oldham, G.R. (1976). Motivation through the design of work: Test of a theory. Organizational Behavior and Human Performance, 16(2), 250-279, doi: 10.1016/0030-5073(76) 90016-7. 
REGE 28,3

Hair, J.F. Jr, Hult, G.T.M., Ringle, C., \& Sarstedt, M. (2016). A Primer on Partial Least Squares Structural Equation Modeling (PLS-SEM). Sage Publications.

Hair, J. F. Jr., Risher, J.J., Sarstedt, M., \& Ringle, C.M. (2019). When to use and how to report the results of PLS-SEM. European Business Review, 31(1), 2-24, doi: 10.1108/EBR-11-2018-0203.

Hallak, R., Assaker, G., O'Connor, P., \& Lee, C. (2018). Firm performance in the upscale restaurant sector: The effects of resilience, creative self-efficacy, innovation and industry experience. Journal of Retailing and Consumer Services, 40, 229-240, doi: 10.1016/j.jretconser.2017.10.014.

Harmancioglu, N., Sääksjärvi, M., \& Hultink, E.J. (2020). Cannibalize and combine? The impact of ambidextrous innovation on organizational outcomes under market competition. Industrial Marketing Management, 85, 44-57, doi: 10.1016/j.indmarman.2019.07.005.

Hua, J., \& Shaw, R. (2020). Corona virus (Covid-19) 'infodemic' and emerging issues through a data lens: The case of China. International Journal of Environmental Research and Public Health, 17(7), 1-12, doi: 10.3390/ijerph17072309.

Hunt, R.A. (2013). Entrepreneurial tweaking: An empirical study of technology diffusion through secondary inventions and design modifications by start-ups. European Journal of Innovation Management, 16(2), 148-170, doi: 10.1108/14601061311324511.

Kantur, D.Z., \& Iseri-Say, A. (2012). Organizational resilience: A conceptual integrative framework. Journal of Management \& Organization, 18(6), 762-773, doi: 10.5172/jmo.2012.18.6.762.

Kaya, B., Abubakar, A.M., Behravesh, E., Yildiz, H., \& Mert, I. S. (2020). Antecedents of innovative performance: Findings from PLS-SEM and fuzzy sets (fsQCA). Journal of Business Research, 114, 278-289, doi: 10.1016/j.jbusres.2020.04.016.

Kraus, S., Ribeiro-Soriano, D., \& Schüssler, M. (2018). Fuzzy-set qualitative comparative analysis (fSQCA) in entrepreneurship and innovation research-the rise of a method. International Entrepreneurship and Management Journal, 14(1), 15-33, doi: 10.1007/s11365-017-0461-8.

Kuckertz, A., Brändle, L., Gaudig, A., Hinderer, S., Reyes, C.A.M., Prochotta, A., Steinbrink, K.M., \& Berger, E.S. (2020). Startups in times of crisis-A rapid response to the COVID-19 pandemic. Journal of Business Venturing Insights, 13, 1-13, e00169, doi: 10.1016/j.jbvi.2020.e00169.

Lin, H.E., McDonough, E. F. III, Lin, S.J., \& Lin, C.Y.Y. (2013). Managing the exploitation/exploration paradox: The role of a learning capability and innovation ambidexterity. Journal of Product Innovation Management, 30(2), 262-278, doi: 10.1111/j.1540-5885.2012.00998.x.

Mahama, H. \& Cheng, M. M. (2013). The effect of managers' enabling perceptions on costing system use, psychological empowerment, and task performance. Behavioral Research in Accounting, 25(1), 89-114. doi: 10.2308/bria-50333.

Manley, S.C., Hair, J.F., Williams, R.I., \& McDowell, W.C. (2020). Essential new PLS-SEM analysis methods for your entrepreneurship analytical toolbox. International Entrepreneurship and Management Journal, 1-21, doi: 10.1007/s11365-020-00687-6.

McCann, J. (2004). Organizational effectiveness: Changing concepts for changing environments. Human Resource Planning, 27(1), 42-51.

Monteiro, J.J., \& Beuren, I.M. (2020). Efeitos do debate do sistema de mensuração de desempenho e do conflito cognitivo na inovação ambidestra. Revista de Contabilidade e Organizações, 14, 1-12, doi: 10.11606/issn.1982-6486.rco.2020.170418.

Nitzl, C. (2016). The use of partial least squares structural equation modelling (PLS-SEM) in management accounting research: Directions for future theory development. Journal of Accounting Literature, 37, 19-35, doi: 10.1016/j.acclit.2016.09.003.

Orth, M., \& Volmer, J. (2017). Daily within-person effects of job autonomy and work engagement on innovative behaviour: The cross-level moderating role of creative self-efficacy. European Journal of Work and Organizational Psychology, 26(4), 601-612, doi: 10.1080/1359432X.2017.1332042.

Pejić-Bach, M. (2021). Electronic commerce in the time of covid-19-perspectives and challenges. Journal of Theoretical and Applied Electronic Commerce Research, 16(1), 1, doi: 10.4067/S071818762021000100101. 
Podsakoff, P.M., \& Organ, D.W. (1986). Self-reports in organizational research: Problems and prospects. Journal of Management, 12(4), 531-544, doi: 10.1177/014920638601200408.

Podsakoff, P.M., MacKenzie, S.B., Lee, J.Y., \& Podsakoff, N.P. (2003). Common method biases in behavioral research: A critical review of the literature and recommended remedies. Journal of Applied Psychology, 88(5), 879-903, doi: 10.1037/0021-9010.88.5.879.

Ragin, C. C. (1987). The Comparative Method: Moving Beyond Qualitative and Quantitative Strategies. California: University of California Press.

Ragin, C.C. (2000). Fuzzy-set Social Science. Chicago: University of Chicago Press.

Ragin, C.C. (2008). Redesigning Social Inquiry: Fuzzy Sets and Beyond. Chicago: University of Chicago Press.

Raisch, S., \& Birkinshaw, J. (2008). Organizational ambidexterity: Antecedents, outcomes, and moderators. Journal of Management, 34(3), 375-409, doi: 10.1177/0149206308316058.

Reinartz, W., Haenlein, M., \& Henseler, J. (2009). An empirical comparison of the efficacy of covariance-based and variance-based SEM. International Journal of Research in Marketing, 26(4), 332-344, doi: 10.1016/j.ijresmar.2009.08.001.

Ringle, C.M., Silva, D., \& Bido, D.S. (2014). Modelagem de equações estruturais com utilização do SmartPLS. Revista Brasileira de Marketing, 13(2), 56-73, doi: 10.5585/remark.v13i2.2717.

Ringle, C.M., Wende, S., \& Becker, J.M. (2015). SmartPLS 3. Boenningstedt: SmartPLS GmbH.

Rodríguez, I., Bravo, M.J., Peiró, J.M., \& Schaufeli, W. (2001). The demands-control-support model, locus of control and job dissatisfaction: A longitudinal study. Work and Stress, 15(2), 97-114, doi: $10.1080 / 02678370110066968$.

Salamzadeh, A., \& Dana, L. P. (2020). The coronavirus (COVID-19) pandemic: Challenges among Iranian startups. Journal of Small Business and Entrepreneurship, 1-24, doi: 10.1080/08276331. 2020.1821158.

Samagaio, A., Crespo, N.F., \& Rodrigues, R. (2018). Management control systems in high-tech startups: An empirical investigation. Journal of Business Research, 89, 351-360, doi: 10.1016/j. jbusres.2017.12.028Get.

Sarkees, M., \& Hulland, J. (2009). Innovation and efficiency: It is possible to have it all. Business Horizons, 52(1), 45-55, doi: 10.1016/j.bushor.2008.08.002.

Sarstedt, M., Hair, J.F. Jr., Ringle, C.M., Thiele, K.O., \& Gudergan, S.P. (2016). Estimation issues with PLS and CBSEM: Where the bias lies!. Journal of Business Research, 69(10), 3998-4010, doi: 10. 1016/j.jbusres.2016.06.007.

Sarstedt, M., Hair, J.F. Jr, Cheah, J.H., Becker, J.M., \& Ringle, C.M. (2019). How to specify, estimate, and validate higher-order constructs in PLS-SEM. Australasian Marketing Journal, 27(3), 197-211, doi: 10.1016/j.ausmj.2019.05.003.

Sauermann, H. (2018). Fire in the belly? Employee motives and innovative performance in start-ups versus established firms. Strategic Entrepreneurship Journal, 12(4), 423-454, doi: 10.1002/sej.1267.

Spender, J.C., Corvello, V., Grimaldi, M., \& Rippa, P. (2017). Startups and open innovation: A review of the literature. European Journal of Innovation Management, 20(1), 4-30, doi: 10.1108/EJIM-122015-0131.

StartupBase (2020). Encontre todas as startups do Brasil: A maior e mais completa base de dados do ecossistema brasileiro de startups, Recuperado de 2020, available at: https://startupbase.com.br/ home. Acesso em 21 ago.

Su, J., Zhang, S., \& Ma, H. (2019). Entrepreneurial orientation, environmental characteristics, and business model innovation: A configurational approach. Innovation, 22(4), 1-23, doi: 10.1080/ 14479338.2019.1707088.

Theiss, V., \& Beuren, I. M. (2020). Reflexes of application of funds on the design and use of the management control system. Journal of Accounting, Management and Governance, 23(2), 218-234, doi: 10.21714/1984-3925_2020v23n2a5.

Brazilian startups in Covid-19 crisis 
REGE

28,3

Vargas, C.A.F., \& Plonski, G.A. (2019). The contribution of technology parks to high-tech startups. In Startups and Innovation Ecosystems in Emerging Markets. Cham: Palgrave Macmillan, 99-118, doi: 10.1007/978-3-030-10865-6_6.

Verma, S., \& Gustafsson, A. (2020). Investigating the emerging COVID-19 research trends in the field of business and management: A bibliometric analysis approach. Journal of Business Research, 118, 253-261, doi: 10.1016/j.jbusres.2020.06.057.

Woodside, A. G. (2013). Moving beyond multiple regression analysis to algorithms: Calling for adoption of a paradigm shift from symmetric to asymmetric thinking in data analysis and crafting theory. Journal of Business Research, 66(4), 463-472, doi: 10.1016/j.jbusres.2012.12.021.

\section{Corresponding author}

Anderson Betti Frare can be contacted at: anderson_betti_frare@hotmail.com

Associate Editor: Rodrigo Morais-da-Silva

For instructions on how to order reprints of this article, please visit our website: www.emeraldgrouppublishing.com/licensing/reprints.htm Or contact us for further details: permissions@emeraldinsight.com 